\title{
El Diccionario militar de Federico Moretti y su apéndice metrológico: sobre el análisis de la nomenclatura del sistema métrico decimal"
}

\author{
FRANCISCO JAVIER SÁNCHEZ MARTÍN \\ Universidad de Murcia
}

\section{INTRODUCCIÓN}

Las Etimologías de San Isidoro ${ }^{1}$ constituyen una de las primeras fuentes para el estudio de la metrología. Esta obra testimonia el interés constante de los hombres durante toda la historia por compendiar las unidades referidas a pesos y medidas. La herencia de los distintos pueblos y culturas posibilitó la variabilidad de los patrones y la falta de correspondencia unívoca entre el significante y la designación, dificultada además por el carácter mutable de los propios valores mensurales y ponderales.

En la antigüedad los nombres de las primeras unidades estuvieron vinculadas al hombre (etapa antropométrica), esto es, lo tenían como punto de referencia esencial (patrones como pie o paso), así como a las distintas actividades asociadas o desempeñadas por él (legua, jornada o huebra).

Por otra parte, existía una gran cantidad de medidas (pie, estadal, vara o legua) para una misma magnitud - la longitud, en este caso-, que eran diferentes en función del objeto medible (la arroba de peso y la de aceite o la libra y la libra medicinal) y variaban de unos territorios a otros, lo que dificultaba el comercio, propiciaba los abusos, al tiempo que exigía la conversión entre ellas. En definitiva, el sistema tradicional era aparentemente caótico, razón que motiva los reiterados intentos de unificación que, sin embargo, han fracasado continuamente ${ }^{2}$. Como consecuencia inevitable, desde época temprana surgieron obras sobre esta temática, cuyo número se incrementó a partir del Renacimiento debido al auge de las actividades comerciales. Entre sus cometidos co-

* Esta investigación se ha realizado merced al proyecto investigación El diccionario de la ciencia y de la técnica del Renacimiento (DICTER): implantación definitiva en la red (FFI2013-41386-P), financiado por el Ministerio de Economía y Competitividad. Agradezco, por otro lado, a Marta Sánchez Orense la localización de este vocabulario metrológico, así como la posibilidad de poder consultarlo.

${ }^{1}$ En el libro XVI San Isidoro dedica dos capítulos a los pesos y medidas: 25. De ponderibus y 26. De mensuris. «Resulta muy conveniente el conocimiento de los pesos y las medidas, pues todas las cosas corporales, según está escrito, desde lo más elevado a lo más humilde, fueron dispuestas y formadas de acuerdo con una medida, un número y un peso» (apud Oroz Reta y Marcos Casquero 1982-1983: 313).

${ }^{2}$ Ya desde los últimos siglos medievales, en los reinos de Castilla y León, dan comienzo peticiones de los representantes de las ciudades para que se procure una reducción en la confusa variedad que se padece. Las protestas continuarán en las centurias siguientes. En otros países, como apunta Maravall (1986² : 66), la tendencia es análoga: así en Francia e Inglaterra, a finales del siglo XVII, la diversidad en las medidas es todavía grande.

FRANCISCO JAVIER SÁNCHEZ MARTÍN

«El Diccionario militar de Federico Moretti y su apéndice metrológico: sobre el análisis de la nomenclatura del sistema métrico decimal», Revista de Lexicografía, XXI (2015), pp. 117-130 
munes estaba el proporcionar los valores, facilitar las equivalencias y, finalmente evitar los fraudes, para lo que se disponían tablas y listados.

Todavía a comienzos del siglo XIX se procede al último intento, la enésima propuesta de reforma y unificación de los antiguos patrones que se realiza mediante la Real Orden de 26 de enero de 1801. Este postrero esfuerzo nacional por conseguir la uniformidad entre los valores de nuestras medidas tradicionales ${ }^{3}$ convive con los aires de reforma, esto es, con la reciente aparición del sistema métrico decimal, de ahí que todas las obras posteriores - recopilaciones, glosarios, diccionarios - se centren en establecer ahora las equivalencias entre aquellas y las del nuevo sistema métrico, emulando el habitual proceder de los materiales precedentes en que se fijaban las correspondencias con las monedas y medidas de otros territorios.

Por fin el siglo XVIII alumbra en Francia un proyecto de unificación con la escala decimal como base, propuesta que ha sido reconocida como «uno de los caracteres definitorios del estado moderno europeo» (Ten Ros 1989: 102). Sin duda, esta empresa era posible gracias a las transformaciones sociales, a los cambios de mentalidad y a las necesidades que demandaba la sociedad industrializada: «en la nueva era que soñaban los revolucionarios franceses, toda la humanidad debía gozar de las mismas ventajas. La nueva medida debía ser universal» (Ten Ros 2000: 1). El novedoso sistema decimal era el primer paso hacia la constitución del sistema internacional de unidades de medida. De acuerdo con Lorenzo Pardo (1998: 13), nació «con tres características esenciales: su afán unificador, su espíritu universal y su naturaleza decimal», lo que ineludiblemente tendrá consecuencias para la fijación de una terminología también colectiva y biunívoca.

Por lo que respecta a nuestro país, la primera ley española sobre el establecimiento del sistema métrico data de 1849 , cuya promulgación fue dictada por Isabel II y conllevó la aparición de múltiples textos de todo tipo para lograr divulgarlo (Gutiérrez y Peset 1997: 37). Ahora bien, de acuerdo con Ten Ros (2000: 6), hasta 1880 no se aplicaría esta de modo obligatorio en España, pese a producirse la oficialización del metro en nuestro país en 1868 (Ten Ros 1989: 114) ${ }^{4}$. Posiblemente, la Real Academia Española no decidiera incluir esta nomenclatura en el diccionario oficial hasta su implantación definitiva en España, de ahí que la edición de 1869 ya la incorporase. La recepción de esta terminología en el diccionario académico prueba su rápida aclimatación en nuestra lengua, si bien gozó de más temprana aparición en distintos manuales científicos o en productos lexicográficos especializados, según atestigua la obra de Federico Moretti. Ello no evitó que siguieran publicándose catálogos con las medidas arraigadas,

${ }^{3}$ Pero en esta disposición legal se constata el fuerte peso de la tradición: «Los médicos y boticarios continuarán usando la libra medicinal de doce onzas iguales a las onzas del marco español, para evitar los daños que de alterarla podrían resultar a la salud pública» (Lorenzo Pardo 1998: 49).

${ }^{4}$ Paralelamente a la acuñación de estas medidas universales, continuaban los intentos en otros ámbitos (Marina) y los empeños (Císcar) de adaptación del mismo para el caso de España (Gutiérrez y Peset 1997). Cabe subrayar la empresa de Jorge Juan, Antonio Bordázar o Mayans por encontrar un patrón de medida universal que no estuviera ligado con ningún estado. Todas estas inicativas pueden resumirse con estas palabras: «La única consecuencia destacable del trabajo de Gabriel Ciscar y los metrólogos españoles de principios del siglo XIX, fue la fijación definitiva de las equivalencias entre los patrones castellanos y los del sistema métrico decimal» (Ten Ros 2002: 415). 
como las «Observaciones dirigidas á averiguar las medidas y pesos corrientes, ó imaginarios, que están en uso en las diferentes provincias de España é islas adyacentes» (Real Academia de la Historia 1898), ni que los repertorios continuaran ofreciendo la traducción con las antiguas para facilitar su emple ${ }^{5}$.

\section{EL DICCIONARIO MILITAR ESPAÑOL-FRANCÉS: EXAMEN DE SU ESTRUCTURA}

La primera referencia biográfica sobre el militar Federico Moretti la proporcionan Laplane y Ricard (1963). Por su parte, Carpintero Fernández (2009: 112) ${ }^{6}$ muestra la otra faceta más conocida, la de guitarrista y compositor. Son célebres las composiciones musicales, así como los métodos para guitarra que publicó, aunque Moretti no descuidó su principal labor profesional. A partir de 1812, durante su estancia en Cádiz, de la que sabemos por la mención que hace de ello él mismo en el prólogo de su obra, comienza a redactar el Diccionario militar español-francés que finalmente será publicado en Madrid, el año de 1828. La parte preliminar de este diccionario está constituida por las cuarenta páginas que comprenden la dedicatoria a Fernando VII, el prólogo, el texto con la «Provisión y ordenanza de los Señores Reyes Católicos para que todos tuviesen armas en su casa y poder», dada el 18 de septiembre de 1495; a los que siguen el aparato bibliográfico y la fe de erratas, además de un breve índice con la explicación de las abreviaturas.

El prólogo del diccionario contiene el proceder lexicográfico con las pautas para la redacción de la obra. El razonamiento del lexicógrafo nos descubre que su obra es un diccionario de lengua, ya que se atiene a la definición de las voces y prescinde de la información histórica complementaria con la que solían sus coetáneos adornar sus obras ${ }^{7}$. Ello no impide que, en numerosas ocasiones, se aparte de sus propósitos. Veamos su declaración de intenciones:

Los más de los Diccionarios militares que he consultado incurren generalmente en el defecto de exceder los límites que no debe traspasar un lexicógrafo, y no contentos con dar el significado preciso de la voz y su definición, refieren su etimología, las trasformaciones que ha sufrido y la legitimidad de su uso, lo que hace penoso su manejo y resfría la curiosidad de muchos, que arredrados del tamaño y extensión no quieren tomarse el trabajo de consultarlos para salir de sus dudas (Moretti 1828: IX-X).

También en esta parte inicial Moretti informa de la considerable terminología metrológica que atesora su obra, de la que nos ocuparemos más adelante, y apunta que

Siguiendo el plan de sujetarme á las reglas de un Diccionario habia intercalado los nombres de los pesos, medidas y monedas antiguas y modernas, explicándolas en sus letras respectivas; pero habiéndome insinuado mi erudito censor ${ }^{8}$ que sería

\footnotetext{
${ }^{5}$ Pascual Fernández (2008) realiza un estudio en las ediciones del diccionario académico del siglo XIX.

${ }^{6}$ Esta investigadora reproduce los datos biográficos que contiene el expediente personal custodiado en el Archivo General Militar de Segovia, ya manejados por Laplane y Ricard (1963).

${ }^{7}$ Confróntese éste con otros diccionarios de carácter eminentemente enciclopédico confeccionados durante los siglos XVIII y XIX, de cuyo examen se ocupa Sánchez Orense (2012).

${ }^{8}$ En nota precisa: «El Señor Don Martín Fernández de Navarrete, bien conocido en la república de las letras».
} 
mejor formar un tratadito separado de la materia por via de apéndice, lo he verificado asi, bien convencido de la importancia de este asunto (Moretti 1828: XI).

Por su parte, entre estos preliminares del diccionario se encuentran las 21 páginas destinadas a la «noticia de las obras latinas, castellanas, italianas, francesas, inglesas y alemanas que se han consultado para la redacción de este Diccionario y su Apéndice». Este catálogo constituye el corpus empleado para la redacción del mismo, una selección de cerca de 300 obras que evidencia la extraordinaria erudición del militar ${ }^{9}$. Relacionamos los títulos de los que se valió para compilar el vocabulario metrológico entre los que destacan los manuales de los siglos XVII y XVIII, pero además sobresalen algunas obras contemporáneas, como la Memoria elemental sobre los nuevos pesos y medidas (1800) o el Manuel pratique et élémentaire des poids et mesures et du calcul décimal ${ }^{10}$ :

Academia española (Real). Diccionario de la lengua española. Quinta edición. Madrid, 1817.

Agricola. Tabulae nummariae Romanorum Gregorumque, ad Belgicam, Galliam, Hispaniam et Italicam monetam revocatae. Antuerpiae, 1616.

Aparaci. Norte fijo y prontuario para la mas clara y breve inteligencia del valor de las monedas, \&c. Madrid, 1741.

Caballero. Breve cotejo y balance de las pesas y medidas de varias naciones \&c. comparadas con las de España. Madrid, 1731.

Cantos Benitez. Escrutinio de maravedises y monedas de oro antiguas \&c. Madrid, 1763.

Ciscar. Memoria elemental sobre los nuevos pesos y medidas decimales \&c. Madrid.

Ciscar. Apuntes sobre medidas, pesos y monedas. Madrid, 1821.

Ezpeleta. Resoluciones sobre la baja de la moneda en España \&c. Madrid, 1654.

Ferreria. Nuevo tratado de reducción de monedas \&c. Madrid, 1803.

Lucuze. Medidas militares. Barcelona, 1773.

Marien y Arróspide. Tratado general de monedas, pesas y medidas. Madrid, 1789.

Martín Gómez. Manual de comercio, o descripción de las monedas, pesas y medidas de los reinos de España \&c. Madrid, 1795.

P.J.M.A. Prontuario ó razón de todas las monedas de oro, plata, vellón e imaginarias \&c. Madrid, 1804.

Saez. Demonstración histórica del verdadero valor de todas las monedas españolas \&c. Madrid, 1805.

Sala y Xapran. Disertaciones sobre el valor efectivo de las monedas de Castilla, Aragón y Navarra \&c. (memorias de la academia de la historia).

Tarbé des Sablons. Manuel practique et élémentaire des poids, mesures et monnaies. Paris, 1828.

Tras este apéndice bibliográfico y la fe de erratas, se halla el índice con la explicación de las abreviaturas empleadas. Entre ellas se incluyen las correspondientes a la marcación diatécnica, así constan Alb. (Albeitería), Alg. (Álgebra), Art. (Artillería),

${ }^{9}$ «[...] Une marque de cette vaste curiosité qu'atteste la diversité de ses ouvrages et qui est peut-être le fruit de l'education qu'il reçut au siècle des "lumières"» (Laplane y Ricard 1963: 46).

${ }^{10}$...contenant les instructions les plus propres à familiariser avec la connaissance du nouveau système, et un grand nombre de tables de comparaison basées sur le mètre et le kilogramme définitifs de Sébastien-André Tarbé des Sablons. 
Blas. (Blasón), Cab. (Caballería), Esg. (Esgrima), Fort. (Fortificación), Gen. (Gineta), O. M. (Orden militar), Pic. (Picadero o Equitación).

No obstante, el elenco de abreviaturas está incompleto, puesto que están ausentes las marcas utilizadas para marcar las voces geométricas, como cotejamos en rombo y romboide. El sistema de marcación es sistemático, dado que se excluye la abreviatura Geom. de voces como cúneo que, aunque posee un sentido técnico geométrico, aquí está lematizada por referirse específicamente a una formación táctica.

RomBo. Geom. Rhombe. Rectilíneo que consta de cuatro lados iguales y de ángulos desiguales.

ROMBOIDE. Geom. Rhomboide. El cuadrilongo cuyos ángulos y lados son desiguales. CúNEO. ant. Formation en coin, ou tête de porc. Orden triangular de batalla en forma de un cono truncado que termina en punta por el frente y se ensancha hacia la base. Le usaron mucho los griegos y romanos para romper la línea enemiga; y generalmente le formaban con las tropas de reserva. Al cúneo se le oponía el orden de tenaza.

A continuación, se incorpora el Diccionario militar. Con el suplemento de algunas voces suprimidas en el Diccionario que comprende un total de cuatrocientas cuarenta y ocho páginas. El proceder habitual de cualquier diccionario bilingüe es especificar tras cada lema el equivalente o los equivalentes correspondientes en la otra lengua tratada; sin embargo, nuestro autor decide además incorporar para cada entrada léxica una definición y las informaciones o explicaciones que resulten oportunas.

Los siguientes materiales léxicos suman un total de ciento noventa y cinco páginas que integran el Apéndice al diccionario militar castellano y francés, que según reza «contiene el manual alfabético razonado de las monedas, pesos y medidas de todos los tiempos y países, con sus reducciones a las equivalencias españolas y francesas», así como un Suplemento de algunas voces suprimidas en el Apéndice.

Como ya advertimos, Moretti sometió su diccionario a las consideraciones de Martín Fernández de Navarrete ${ }^{11}$, quien le aconsejó retirar la información relativa a pesos, medidas y monedas, que había insertado previamente junto con las voces de la milicia. El presente Apéndice demuestra que el criterio del científico y académico fue atendido. Insertamos una pequeña muestra de estas medidas y monedas con el fin de reflejar que el napolitano cumple con lo prometido en esta parte de su obra. Al igual que todos los autores se vale del recurso a las equivalencias, de ahí que los valores estén entrelazados creándose, a su vez, cadenas de significantes a partir de una unidad base. Por tanto, cada entrada cuenta con una definición que expresa su valor y a la que acompañan los equivalentes en los distintos países o territorios.

Copa. Coupe. Pequeña medida de vino en Madrid y parte de Castilla la Nueva: 4 copas hacen un cuartillo.

${ }^{11}$ Bajo la dirección de Gabriel Ciscar se dedicó al estudio de las matemáticas con aplicación a la astronomía, navegación, maniobra y arquitectura naval (apud Enciclopedia universal ilustrada europeoamericana 1928: s. v. Fernández de Navarrete). 
Litron. Litron. Pequeña medida para áridos en Francia: 16 litrones hacen un boisso; y 192 un setier: corresponde á una octava parte del celemín de Castilla. (Véase sistema métrico).

Mills. Mills. Moneda de cobre de los Estados Unidos del norte de América: 10 mills hacen un cent; y equivale á 6 1/8 maravedís de vellón, y á un sueldo, moneda de Francia.

Vaquias. Vakias. Pesa en las Indias Orientales: equivale casi á una libra, peso de Inglaterra. También se da este nombre á una medida de aquel país.

Velta. Velte. Medida de líquidos que se usaba en Francia: contenía 8 pintas de Paris: ahora se llama sitier ó verja.

Voya. Voye. Medida cúbica en Francia para piedras, maderas y leña: contiene 4 pies cúbicos de Paris en todos los sentidos. Para el carbón de piedra se divide en las siguiente fracciones $[\ldots]$

Zolotusque. Zolotusk. Pesa en Rusia: contiene 70 gramos; y se divide en mitades, cuartas y octavas partes.

En otros casos el artículo lexicográfico es más amplio y exhaustivo al citarse todas las correspondencias posibles, como sucede con vara, cuyo artículo se extiende de la página 162 a la 170 :

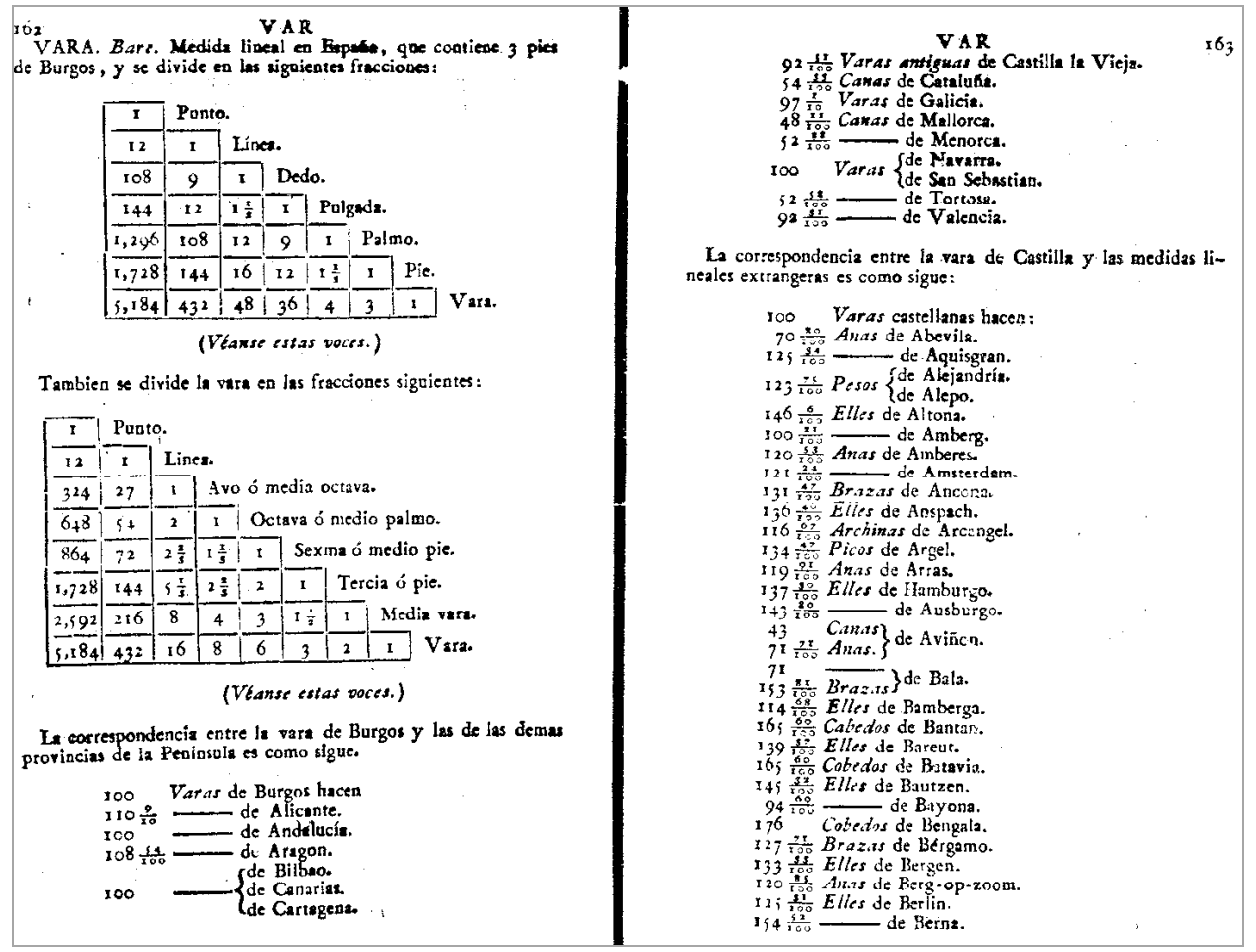

Por último, se sitúa el Vocabulaire français-espagnol faisant suite au dictionaire militaire espagnol-français par le même auteur, que consta de setenta y dos páginas. En esta parte bilingüe, constatamos que todos los lexemas concernientes al sistema métrico van acompañados también por la marca de especialidad: mes. 'mesure' o pd. 
'poid', según proceda, además del equivalente en castellano, tanto en las unidades principales (Are. mes. Área; Gramme. pd. Gramo; Litre. mes. Litro; Mètre. mes. Metro; Stère. mes. Esterio), como en el caso de las unidades divisoras (Décalitre. mes. Decálitro; Décagramme. pd. Decágramo; Hectolitre. mes. Hectolitro; etc.).

\section{EL MANUAL ALFABÉTICO RAZONADO Y LAS ENTRADAS REFERENTES AL SISTEMA MÉTRICO}

La primera documentación lexicográfica española, de la que tenemos noticia, sobre la referencia al sistema métrico decimal la constituye el Manual alfabético razonado de las monedas, pesos y medidas objeto de análisis. Su implantación legal obligatoria en España tardaría, por lo que es lógico que durante toda la primera mitad del siglo XIX sea usual el empleo de los sistemas tradicionales en otros ámbitos especializados, como demuestra el informe, Viage metalúrgico por el litoral del mediterráneo (1848), redactado por Luis de la Escosura, donde se expresan las cantidades en onzas, adarmes y granos, también los quintales de plata que contienen las minas; o las distancias de altura se indican por varas y las dimensiones de los hornos en pies y pulgadas (vid. Díez de Revenga Torres y Puche Lorenzo 2008: 27, 69, 71).

Con respecto a la lematización de la terminología métrica, el artículo lexicográfico correspondiente a sistema métrico contiene la información sobre las unidades fundamentales de medida para cada magnitud: aere, estério, gramo, metro, litro, además de los términos empleados para designar los múltiplos y submúltiplos de las mismas ( $c f$. Moretti 1828: 177).

SISTEMA MÉTRICO. Système méthrique. Unidades de pesas y medidas. El sistema métrico adoptado en Francia está fundado sobre la partición y multiplicación decimal de las cinco cantidades primordiales que le sirve de base, y por las cuales han fijado cinco voces ó nombres propios, que son:

Aere ... Unidad primordial y céntrica para las medidas de superficie.

Estério ... Unidad primordial y céntrica para las medidas cúbicas.

Gramo... Unidad primordial y céntrica para las pesas.

Metro... Unidad primordial y céntrica para las medidas lineales.

Litro... Unidad primordial y céntrica para las medidas de capacidad.

Dichas unidades se parten ó multiplican con el auxilio de los decimales, cuyas particiones ó multiplicaciones se expresan por medio de siete voces adicionales, tres para las primeras y cuatro para las segundas, y son:

Partición.

Mili... La milésisma parte de la unidad.

Centi... La centésisma parte idem.

Deci... La décima parte idem.

Multiplicación.

Deca... Diez veces la unidad.

Hecto... Cien veces idem.

Quilo... Mil veces idem.

Miria... Diez mil veces idem.

Estas voces, unidas a las que expresan las principales unidades, originan la nueva terminología metrológica. Moretti inserta unas tablas con las equivalencias entre estas medidas y las antiguas, pero junto a ellas ofrece otra tabla general con las distintas correspondencias (vid. tabla adjunta). Reproduce, en primer lugar, los valores tal como 
fueron aprobados en la Asamblea nacional francesa el 26 de marzo de 1791: el metro ${ }^{12}$ sería la diezmillonésima parte del cuadrante del meridiano terrestre, la medida de capacidad sería el decímetro cúbico y la de peso el equivalente a un centímetro cúbico lleno de agua ( $c f$. Ten Ros 2000).

\begin{tabular}{|c|c|c|c|c|c|c|}
\hline \multicolumn{7}{|c|}{ TABLA. GENER AL. } \\
\hline \multirow{2}{*}{$\begin{array}{l}\text { Proporcion entre la } \\
\text { unidad y has parti- } \\
\text { c ciones y multiplica- } \\
\text { ciones de cada peso } \\
\text { y medida. }\end{array}$} & \multirow{2}{*}{$\begin{array}{l}\text { Primera parre de } \\
\text { los nousbres de ca- } \\
\text { da peso y ne- } \\
\text { dida. }\end{array}$} & \multicolumn{5}{|c|}{$\begin{array}{c}\text { UNIDADES JEL SISTEMA METRICO FRANCES, Ó NOMBRES PROPIOE } \\
x \text { PRIMORDIALES DE } \text { LAS PESAS Y MgDIDAS. }\end{array}$} \\
\hline & & Medida lineat. & $\begin{array}{l}\text { Medida } \\
\text { de capacidact. }\end{array}$ & Pes.. & $\begin{array}{c}\text { Medida } \\
\text {-grimensotia. }\end{array}$ & Medida cóblç. \\
\hline 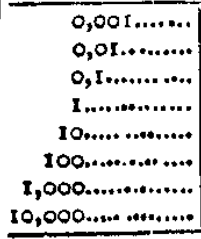 & 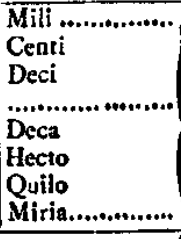 & METRO. & LITRO. & GRAMO. & AREA. & ESTERIO. \\
\hline \multicolumn{2}{|c|}{$\begin{array}{l}\text { Proporcion de las principales me- } \\
\text { didas entre ellas mismas, y la } \\
\text { longtud del meridiano. }\end{array}$} & $\begin{array}{l}\text { Diezmilioné- } \\
\text { sima partede } \\
\text { la distancia } \\
\text { entre el polo } \\
\text { y el ecuador. }\end{array}$ & $\begin{array}{c}\text { Un decímetro } \\
\text { cúbico. }\end{array}$ & $\begin{array}{l}\text { Peso de un } \\
\text { centímetro } \\
\text { cúbico } \\
\text { de sgura. }\end{array}$ & $\begin{array}{l}\text { Cien metros } \\
\text { cuadrados. }\end{array}$ & $\begin{array}{l}\text { Un metro cu- } \\
\text { bico. }\end{array}$ \\
\hline \multicolumn{2}{|c|}{$\begin{array}{l}\text { Correspondencia con las principa- } \\
\text { les medidas y pesas que se usaban } \\
\text { anteriormente en Francia. }\end{array}$} & $\begin{array}{l}3 \text { pies y } \text { I I } \frac{1}{2} \\
\text { lineas escasas. }\end{array}$ & $\begin{array}{l}1 \frac{\pi}{2} \text { pintas ó } 1 \frac{1}{2} \\
\text { litrones es- } \\
\text { casos. }\end{array}$ & $\begin{array}{l}18 \text { granos } \\
y \frac{94}{3060} \text { partes } \\
\text { de otro. }\end{array}$ & $\begin{array}{l}\text { I si pérticas } \\
\text { cuadradas } \\
\text { de } 22 \text { pies } \\
\text { cada utra. }\end{array}$ & $\begin{array}{l}\text { Media roya } \\
\text { ó un cuarto } \\
\text { de cuerda an- } \\
\text { tigua. }\end{array}$ \\
\hline \multicolumn{2}{|c|}{$\begin{array}{l}\text { Valot en pesos y medidas } \\
\text { castellauas. }\end{array}$} & $\begin{array}{l}3 \text { pies y } 7 \\
\text { pulgadas } \\
\text { de Burgos. }\end{array}$ & $\begin{array}{l}3 \frac{97}{900} \text { cuarti- } \\
\text { llos y } 2 \frac{36}{100} \\
\text { celemines } \\
\text { de Castilla. }\end{array}$ & $\begin{array}{l}20-\frac{2}{\text { ing granos }} \\
\text { dẹt inirco } \\
\text { de Avila. }\end{array}$ & $\begin{array}{l}91 \frac{0}{\text { Io }} \text { varos } \\
\text { cuadradas } \\
\text { de Toledo. }\end{array}$ & $\begin{array}{l}46 \frac{1}{2} \text { pies cábi- } \\
\text { cos de Burgos. }\end{array}$ \\
\hline
\end{tabular}

Las siguientes partes de la tabla se destinan a indicar la correspondencia con las medidas usuales tanto en Francia como en España. Con respecto a las españolas, se anotan las equivalencias de las unidades métricas con las tradicionales pesas y medidas castellanas dispuestas en la Real Orden de 1801, aunque en nuestro caso, las medidas se basaban en distintos patrones que eran ya inservibles, según confiesa Ciscar en su Memoria elemental: «la famosa vara de Burgos está torcida y mal escuadrada por sus extremos» (Gutiérrez Cuadrado y Peset 1997: 16).

En la citada disposición legal se fijan los patrones: «Estas normas son el patrón de la vara que se observa en el Archivo de la ciudad de Burgos; el patrón de la media fanega que se conserva en el Archivo del Consejo» (Lorenzo Pardo 1998: 49). De este modo, la adopción para cada magnitud de una unidad raíz constata la relación estrecha con el objeto medible - propia de los sistema tradicionales - y vislumbra la preeminencia de las ciudades castellanas más relevantes en nuestra historia metrológica ${ }^{13}$ : patrón de

${ }^{12}$ La medida denominada metro (gr. metron 'medida') tiene fecha de bautizo, sin embargo, habrá que esperar, como precisan Gutiérrez y Peset (1997: 12) hasta 1795 para que se aplicara la nomenclatura a múltiplos y submúltiplos.

${ }^{13}$ No obstante, los patrones materiales oficiales fueron modificándose, como sucedió con la vara para la medición de los paños: (1261) vara de Toledo; (1348) vara de Burgos; (1435) vara de Toledo; (1496) vara de Toledo; (1568) vara de Burgos o vara castellana (vid. Sánchez Martín y Sánchez Orense 2011: 76). 
longitud: vara de Burgos; patrón de capacidad: fanega de Ávila y patrón de peso: marco de Ávila. Los nuevos patrones, en cambio, eran universalmente reproducibles.

Las siguientes voces metro (metre), litro (litre), gramo (gramme) y área (are) poseen entrada léxica y se acompañan de la definición «Unidad de \{medida lineal e itineraria/capacidad/superficie\} \{peso\} en el sistema métrico». Supone una excepción la entrada estéreo (estère). Además, todos sus respectivos artículos lexicográficos van acompañados de una tabla con los correspondientes múltiplos y submúltiplos, así como de una remisión al artículo lexicográfico sistema métrico.

\begin{tabular}{|c|c|c|c|c|c|c|c|c|c|c|c|c|c|}
\hline \multicolumn{7}{|c|}{ 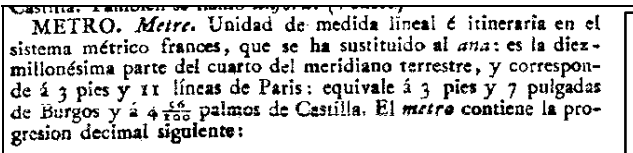 } & \multicolumn{7}{|c|}{$\begin{array}{l}\text { GRAMO. Gramme. Unidad de peso en el sistema métrico: } \\
\text { equivale á r granos del marco de Francia y corresponde á } 20.8 \\
\text { granos de Castilla }(V .) \text {. El gramo contiene la progresion decimal } \\
\text { siguiente: }\end{array}$} \\
\hline & \multirow{3}{*}{$\frac{\text { Milimetro. }}{\mathrm{I}} \mid$ Centimetro. } & \multirow{3}{*}{\multicolumn{5}{|c|}{ Centimetro. }} & 1 & \multirow{2}{*}{$\frac{\text { Miligramo. }}{\mathrm{I}}$} & \multirow{2}{*}{\multicolumn{5}{|c|}{ Centigramo. }} \\
\hline$\Sigma$ & & & & & & & 10 & & & & & & \\
\hline 10 & & & & & & & 100 & 10 & $I$ & \multicolumn{4}{|c|}{ Decigramo. } \\
\hline 100 & 10 & $I$ & \multicolumn{4}{|c|}{ Decimetro. } & 1,000 & 100 & 10 & $I$ & \multicolumn{3}{|c|}{ Gramo. } \\
\hline $8,0,0$ & 100 & 10 & $x$ & \multicolumn{3}{|c|}{ Metro. } & 10,000 & 1,000 & 100 & 10 & $\mathrm{I}$ & \multicolumn{2}{|c|}{ Decagramo. } \\
\hline 10,000 & 1,000 & 100 & 10 & $\mathbf{I}$ & \multicolumn{2}{|c|}{ Decámetro. } & 100,000 & 10,000 & 1,000 & 100 & 10 & \multicolumn{2}{|c|}{ Hectogramo. } \\
\hline 100,000 & 10,000 & 1,000 & 100 & 10 & $I$ & Hectómetro & $1,000,000$ & 100,000 & 10,000 & 1,000 & 100 & $10 / 18$ & Quilogramo. \\
\hline$x, 000,000$ & $100, \infty$ & 10,000 & 1,000 & 100 & 10 & I Quilón & $10,000,000$ & {$[, 000,000$} & 100,000 & 10,000 & $i, 000$ & $100 \mid 10$ & 1 Miriagramo \\
\hline \multirow{2}{*}{\multicolumn{2}{|c|}{$10,000,000, x, 000,000$}} & \multirow{2}{*}{\multicolumn{5}{|c|}{$\frac{\mid 100,000}{(\text { VÉase sishome métrico.) }}$}} & \\
\hline & & & & & & & \multicolumn{6}{|c|}{ (Vtase tistema metrico.) } & \\
\hline & & \multicolumn{9}{|c|}{$\begin{array}{l}\text { EST } \\
\text { de Francis: s estejus hacen el center o quintal de prusia. } \\
\text { ESTERO. Stère. Nuava medida cúbica que se ha adoptado en } \\
\text { Francia para la leña corresponde a un metro cúbico; y equivale } \\
\text { á } 46 \text { pies cúbicos de Castilla. (Véase sistema métrico.) } \\
\text { ESTERLIN. Stcrling. Moneda que corria en Inglaterra, y aun }\end{array}$} & & & \\
\hline
\end{tabular}

La unión de las cinco voces que expresan la unidad medida con las siete raíces que señalan la división y multiplicación decimales da como resultado las unidades métricas, que aparecen especificadas en las tablas bajo los lemas metro, litro, gramo y área, con la salvedad del artículo esterio. Sin embargo, no toda la nomenclatura posee entrada en este apéndice lexicográfico: milimetro, decimetro, decametro; mililitro, decilitro, decalitro; miligramo, decigramo, decagramo; miliárea, deciárea, decárea, quiloárea; además de los compuestos con esterio o los compuestos metro cúbico y metro cuadrado, también sin lematización en el apéndice. Ahora bien, bajo el artículo sistema métrico sí aparecen definidos los únicos términos posibles de área y esterio: centiárea, deciárea, decárea, hectoárea, quiloárea, mirioárea, por un lado; y deciesterio, decaestereo y doble esterio, por otro.

\section{Arca, medida agrimensoria.}

Esta roz no tiene mas particion ó multiplicacion que has siguientes: centiárea ó metro cuadrado: contiene la centésina parte del área.

Deriárea : corresponde $\{$ la decima parte del área.

Hecloárea ó arpinte: es el cuadrado del hectómetro, y contie-

ae roo áreas ó ro,0co metros cuadrados: corresponde 2 arantes de la astigua ordenanza francesa.

Quilosirea: es igual a $\mathrm{T}, 000$ áreas.

Mirioireas contiene 1o oco árcas, y corresponde á un quilotuctro cuadrado. (VEase área.) 


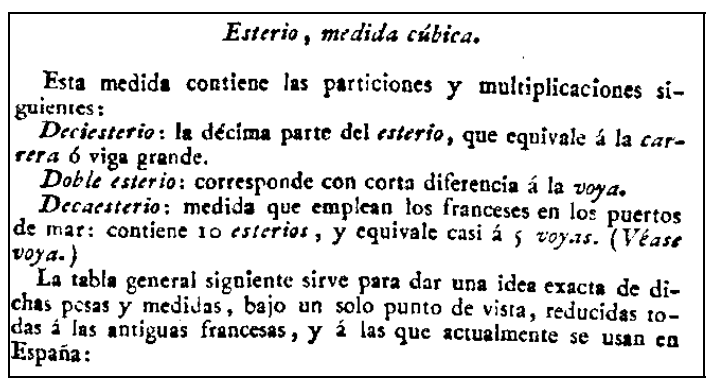

Por otro lado, no habría necesidad de definir por la coherencia del sistema, ya que todas las unidades derivadas usaban un mismo conjunto de múltiplos y submúltiplos decimales obtenidos de las raíces griegas y latinas.

\section{CONSIDERACIONES SOBRE LA NOMENCLATURA DEL SISTEMA MÉTRICO DECIMAL}

Al tiempo que la nomenclatura métrica iba generalizándose, surgieron opiniones críticas con la adaptación del nuevo sistema ${ }^{14}$ y estudios en los que se manifestaban las vacilaciones con respecto a la acentuación fónica y gráfica de estos elementos, que habiendo sido admitidos, sin embargo no se habían aclimatado definitivamente a los patrones fónicos del idioma. Así, Cortázar en su discurso de recepción en la Real Academia Española (1899), plantea directamente estas cuestiones:

Hay otras palabras que, aun después de admitidas sin dificultad morfológica, ofrecen dudas en la pronunciación, cual sucede en varios compuestos del sistema métrico, que el vulgo se obstina en pronunciar como esdrújulos, diciendo quilógramo, hectógramo, decálitro, etc., apartándose de la recta acentuación que, según la cantidad originaria de las sílabas, establece la Academia; y todavía en las mismas palabras métricas hay la dificultad de si las que contienen la representación del múltiplo 1000, es decir, del griego deben escribirse con k, como han hecho desacordadamente los franceses, por atender, contra la índole de su lengua, á la fonética, ó es preferible, ya que no se emplee la ch con sonido duro, [...], usar la q, que la ha sustituído en nuestra ortografía, como poco á poco lo va admitiendo el léxico, para cambiar una letra impropia de nuestro alfabeto y de la razón etimológica con otra que la reemplaza sin desventaja.

Sobre la acentuación Navarro Tomás (1963: 194) anota que a comienzos del siglo pasado abundan las «diferencias de acentuación entre la pronunciación y la escritura» y precisa que

${ }^{14}$ «Mas ha de cumplirse el precepto en toda su integridad y evitar derivaciones absurdas como las que, entre otros muchos casos, han servido para la nomenclatura del sistema métrico de pesas y medidas. Repetidas veces se han criticado los barbarismos acumulados en los nombres de dicho sistema, y sin que tratemos ahora de insistir en tan justas observaciones, nos bastará recordar que las voces, $\mathrm{y}$ traducidas por metro, gramo y litro, para ser las unidades fundamentales de longitud, peso y volumen, significan, respectivamente, en griego medida, línea y libra, bien poco aplicables á los casos en que se han empleado. Partiendo de tan malas bases, resultan absurdos filológicos los nombres de la mayoría de las medidas múltiplas del sistema, así como la designación de las submúltiplas son voces híbridas, todo lo que viene á demostrar el estado lamentable de los estudios clásicos á fines del siglo pasado y principios del actual. A los que quieran conocer la crítica completa de la nomenclatura métrica, recomendamos la lectura del Apéndice á la Grammaire comparée, de Egger (octava edición: París, 1880)» (Cortázar 1899). 
A las palabras poliglota, pentagrama, metamorfosis, metempsicosis, y a otras más corrientes, como miligramo, centigramo, decigramo, centilitro, decalitro, etc., les corresponde acentuación llana según la última edición del Diccionario académico, 1925; pero se pronuncian generalmente como esdrújulas [...]. La acentuación llana se va haciendo corriente en kilogramo y es ya general en epigrama y telegrama, las cuales, sin embargo, aun se usan como esdrújulas fuera del habla culta.

Las búsquedas ejecutadas en el Corpus diacrónico de la Academia (CORDE) muestran, por un lado, que esta terminología estaba muy difundida en los textos correspondientes a la segunda mitad del siglo XIX coleccionados en el CORDE; y, por otro, que en esa época era más frecuente con la pronunciación esdrújula y en el caso del término quilo su escritura con $k$, según puede constatarse en el presente cuadro ${ }^{15}$. En él establecemos, primero, los términos extraídos de las distintas tablas con la escritura por la que opta Moretti; en segundo lugar, presentamos las primeras documentaciones de estos términos en los repertorios lexicográficos, en este caso a partir de los datos proporcionados por Gutiérrez Cuadrado y Peset (1997); al lado, por último, se ofrecen las dataciones que hemos obtenido del CORDE.

\begin{tabular}{|c|c|c|c|}
\hline \multirow{2}{*}{$\begin{array}{c}\text { MORETTI } \\
\text { (1828) }\end{array}$} & \multicolumn{2}{|c|}{ DOCUMENTACIÓN LEXICOGRÁFICA } & \multirow{2}{*}{ DOCUMENTACIÓN CORDE } \\
\hline & $D R A E$ & OTRAS FUENTES & \\
\hline Milímetro & 1869 & Monlau 1856 & \multirow{3}{*}{ 1853: Fernández de Henestrosa ${ }^{16}$} \\
\hline Centímetro & 1869 & Monlau 1856 & \\
\hline Decímetro & 1869 & Monlau 1856 & \\
\hline decámetro & 1869 & Monlau 1856 & \multirow[t]{2}{*}{ 1904-1905: Benejam ${ }^{17}$} \\
\hline Hectómetro & 1869 & Monlau 1856 & \\
\hline Quilómetro & 1869 & Monlau 1856 & 1845: Guevara ${ }^{18}$ \\
\hline Miriámetro & 1869 & Monlau 1856 & 1862: Rubio $^{19}$ \\
\hline Mililitro & 1869 & Campuzano 1857 & 1904-1905: Benejam \\
\hline Centilitro & 1869 & Monlau 1856 & c 1885: Molinas ${ }^{20}$ \\
\hline Decilitro & 1869 & Monlau 1856 & 1856: Sáez de Montoya ${ }^{21}$ \\
\hline Decálitro & 1869 & Monlau 1856 & 1868: Botella y de Hornos ${ }^{22}$ \\
\hline Hectólitro & 1869 & Monlau 1856 & 1856: Sáez de Montoya \\
\hline Quilolitro & 1869 & Monlau 1856 & 1904-1905: Benejam ${ }^{23}$ \\
\hline Mirialitro & No & No & No \\
\hline Milígramo & 1869 & Monlau 1856 & 1853: Fernández de Henestrosa \\
\hline Centígramo & 1869 & Monlau 1856 & 1868: Botella y de Hornos \\
\hline
\end{tabular}

${ }^{15}$ La RAE permitía la escritura de quilo y kilo. Estas vacilaciones las muestra el cuadro ofrecido por Gutiérrez Cuadrado y Peset (1997: 42).

${ }^{16}$ Traducción de Arte de ensayar con el soplete, cualitativa y cuantitativamente, los minerales, aleaciones y productos metalúrgicos, por C. F. Plattner.

${ }^{17}$ La escuela práctica: obra destinada a promover la enseñanza primaria moderna mediante ejercicios. (1880-1881).

${ }^{18}$ Historia de Curicó. Con «qu» en Menéndez Pelayo, Historia de los heterodoxos españoles

${ }^{19}$ Traducción de la Historia de la conquista del Perú y de Pizarro de Henri Lebrun.

${ }^{20}$ Tratado de maquinaria y de aparatos industriales.

${ }^{21}$ Tratado teórico práctico de metalurgia.

${ }^{22}$ Descripción geológica-minera de las provincias de Murcia y Albacete.

${ }^{23}$ Tan sólo en esta obra con la forma kilolitro (tres ocurrencias). 


\begin{tabular}{|l|l|l|l|}
\hline Decígramo & 1869 & Monlau 1856 & 1853: Fernández de Henestrosa \\
\hline Decágramo & 1869 & Monlau 1856 & $1904-1905:$ Benejam \\
\hline Hectógramo & 1869 & Monlau 1856 & $1899:$ Cortázar $^{24}$ \\
\hline Quilógramo & 1869 & Monlau 1856 & $1853:$ Fernández de Henestrosa $^{25}$ \\
\hline Miriagramo & 1869 & Monlau 1856 & No \\
\hline Miliárea & 1869 & - & No \\
\hline Centiárea & 1869 & Monlau 1856 & $1870^{26}$ \\
\hline Deciárea & 1869 & Campuzano 1857 & No \\
\hline Decárea & 1869 & - & No \\
\hline Hectoárea & 1869 & Monlau 1856 & $1863:$ Monlau $^{27}$ \\
\hline Quiloárea & 1869 & - & No \\
\hline Mirioárea & No & No & No \\
\hline Deciesterio & No & No & No \\
\hline Decaestereo & - & Campuzano 1857 & No \\
\hline doble esterio & No & No & No \\
\hline
\end{tabular}

Por otro lado, hemos realizado una búsqueda en el diccionario académico para conocer en qué fecha hicieron su entrada las voces prefijas que denotan la partición y la multiplicación de las unidades métricas. Todas ellas, sin excepción, aparecen en el DRAE (1884), como puede cotejarse. Hemos decidido añadir la presencia de las mismas en la siguiente edición del diccionario académico (DRAE-1899) en el caso de que se haya producido alguna modificación, bien con respecto a la definición, bien referida a su lematización. Nótese, en este sentido, la homogeneidad de las definiciones.

\begin{tabular}{|l|l|l|}
\hline $\begin{array}{l}\text { DOCUMENTACIÓN } \\
\text { LEXICOGRÁFICA }\end{array}$ & \multicolumn{1}{|c|}{ DRAE-1884 } & \multicolumn{1}{|c|}{ DRAE-1899 } \\
\hline Mili & $\begin{array}{l}\text { Voz que sólo tiene uso como prefijo de } \\
\text { vocablos compuestos, con la significación } \\
\text { de milésima parte; v.gr. milimetro. }\end{array}$ & $\begin{array}{l}\text { Voz que sólo tiene uso como prefijo } \\
\text { de vocablos compuestos, en el } \\
\text { sistema métrico decimal, con la } \\
\text { significación de milésima parte; } \\
\text { v.gr. milimetro. }\end{array}$ \\
\hline Centi & $\begin{array}{l}\text { Voz que sólo tiene uso como prefijo de } \\
\text { vocablos compuestos, con la significación } \\
\text { de cien; v.gr. centímano; o de centésima } \\
\text { parte v.gr. centímetro. }\end{array}$ & \\
\hline Deci & $\begin{array}{l}\text { Voz que sólo tiene uso como prefijo de } \\
\text { vocablos compuestos, con la significación } \\
\text { de décima parte. Decímetro. }\end{array}$ & \\
\hline Deca & $\begin{array}{l}\text { Voz que sólo tiene uso como prefijo de } \\
\text { vocablos compuestos, con la significación } \\
\text { de diez. Decámetro. }\end{array}$ & \\
\hline Hecto & $\begin{array}{l}\text { Voz que sólo tiene uso como prefijo de } \\
\text { vocablos compuestos, con la significación } \\
\text { de cien. Hectómetro. }\end{array}$ & \\
\hline
\end{tabular}

${ }^{24}$ Discurso de Recepción en la RAE.

${ }^{25}$ Con «qu» en Sáez de Montoya Tratado teórico práctico de metalurgia (1856).

${ }^{26}$ Reglamento General para la Ejecución de la Ley Hipotecaria de 29 de octubre de 1870.

${ }^{27}$ Del arcaísmo y el neologismo. 


\begin{tabular}{|l|l|l|}
\hline Quilo & $\begin{array}{l}\text { Quilo. M. Kilo } \\
\text { Kili. Prefijo Kilo. Kiliárea. } \\
\text { Kilo. Voz que sólo tiene uso como prefijo } \\
\text { de vocablos compuestos con la significa- } \\
\text { ción de mil. }\end{array}$ & $\begin{array}{l}\text { Kilo. Voz que, con la significación } \\
\text { de mil, tiene uso como prefijo de } \\
\text { vocablos compuestos }\end{array}$ \\
\hline Miria & $\begin{array}{l}\text { Voz que sólo tiene uso como prefijo de } \\
\text { vocablos compuestos, con la significación } \\
\text { de diez mil; v.gr. miriámetro. }\end{array}$ & $\begin{array}{l}\text { Voz que sólo tiene uso como prefijo } \\
\text { de vocablos compuestos, con la } \\
\text { significación de diez mil, en el sis- } \\
\text { tema métrico decimal. Miriámetro. }\end{array}$ \\
\hline
\end{tabular}

Fijémonos ahora en kilo, voz que entra en el DRAE como prefijo con la significación 'mil', al igual que en el vocabulario de Moretti. En su momento de introducción en la lengua, las lexías especializadas se incorporan con su designación «jerarquizada», pero «al integrarse en la estructura de la lengua adquieren perfil individual, cobran virtualidad dentro de un sistema» (Lorenzo 1981: 13). Por tanto, al divulgarse y llegar con posterioridad a todos los hablantes, «pierden sustancia y precisión». Como advierte Lorenzo (1981: 13), este proceso lo experimentó kilo: en la primera fase designa 'mil metros, mil gramos o mil litros', en la segunda sólo es equivalente de 'mil gramos'.

\section{CONCLUSIONES}

Desde que la Asamblea francesa aprobó la proposición presentada por el secretario perpetuo de la Academia de Ciencias de París en que se sentaron las bases del nuevo sistema metrológico, comenzó el largo proceso hacia la unificación mundial todavía inconcluso, como evidencian las regulaciones actuales, por ejemplo, de Costa Rica donde los comercios deben informar, a partir del presente 12 de marzo, de los precios de productos por gramo, mililitro o centímetro (http://www.columbia.co.cr/noticias-nacionales).

Con respecto a la difusión en España, la orden regia de 1801 supuso un obstáculo para la implantación del sistema métrico, que se produjo definitivamente a finales de esa centuria, pero ello no evitó que durante largo tiempo siguieran usándose las medidas arraigadas, a cuya referencia acude el imaginario colectivo hoy, dos siglos después, si bien con imprecisiones. Por tanto, aunque se haya producido una implantación legal progresiva desde su acunación, en los diversos países se han conservado hasta muy recientemente los términos tradicionales.

El apéndice lexicográfico, Manual alfabético razonado de las monedas, pesos y medidas, de Federico Moretti, a la vez que evidencia el empleo de los distintos sistemas de medición, es una prueba de la aceptación temprana de la terminología métrica decimal, cuya recopilación es de gran utilidad para el estudio histórico de la ciencia metrológica.

\section{REFERENCIAS BIBLIOGRÁFICAS}

CARPINTERo FERnÁNDEZ, A. (2009): «Federico Moretti (1769-1839). I. Vida y obra musical», Nassarre, 25, pp. 109-134.

CORDE. ReAl ACADEmia EsPañola. Corpus diacrónico del español. Disponible en $<$ http://corpus.rae.es/cordenet.html $>$ [Consulta: 6 de noviembre de 2011] 
CORTÁZAR, Daniel de (1899): [Algunas ideas referentes a los neologismos] Discursos leídos ante la Real Academia Española. Disponible en $<$ http://corpus.rae.es/cordenet.html> [Consulta: 06/11/2011].

DíEz De ReVEnga Torres, P. y M. Á. Puche Lorenzo (2009): Viage metalúrgico por el litoral del Mediterráneo, A Coruña, Universidade da Coruña.

DRAE-1884. REAL ACADEMIA ESPAÑOLA (1884): Diccionario de la lengua castellana, Madrid, Gregorio Hernando.

DRAE-1899. REAL ACADEMIA ESPAÑola (1899): Diccionario de la lengua castellana, Madrid, Sres. Hernando y compañía.

Enciclopedia universal ilustrada europeo-americana (1928), Madrid, Espasa Calpe.

GutiéRrez CuAdRADO, J. y J. L. PeSet (1997): Metro y Kilo. El sistema métrico decimal en España, Madrid, Akal.

LAPlANe, G. y R. RICARD (1963): «Federico Moretti et son Diccionario militar españolfrancés», Bulletin Hispanique, 65, 1-2, pp. 35-48.

LORENZO CRIADO, E. (1981): Utrum lingua an loquentes? Sobre las presuntas dolencias y carencias de nuestro idioma (Real Academia Española, Discursos de ingreso). Disponible en $<$ http://www.rae.es/rae/gestores/gespub000001.nsf/(voAnexos)/arch928E D475CA8B8B3C1257148004019AE/\$FILE/lorenzo.htm> [Consulta: 08/02/2012].

Lorenzo Pardo, J. A. (1998): La Revolución del Metro, Madrid, Celeste Ediciones.

MARAVALl, J. A. $\left(1986^{2}\right)$ : Estado moderno y mentalidad social (siglos XV a XVII), Madrid, Alianza Editorial.

MoretTi, F. (1828): Diccionario militar español-francés, Madrid, Imprenta Real.

NAVARro TOMás, T. $\left(1963^{11}\right)$ : Manual de pronunciación española, Madrid, CSIC.

Oroz Reta, J. y M. MARCos CASQuero (1982-1983): Etimologías. San Isidoro de Sevilla, Madrid, Biblioteca de Autores Cristianos.

PASCUAL FERNÁNDEZ, L. (2008): «El sistema métrico decimal en la lexicografía española del s. XIX», en E. Bernal y J. De Cesaris, eds., Proceedings of the XIII Euralex International Congress, Barcelona, Institut Universitari de Lingüística Aplicada, Universitat Pompeu Fabra, pp. 1031-1040.

REAL ACADEMIA DE LA HiSTORIA (1898): «Observaciones dirigidas á averiguar las medidas y pesos corrientes, ó imaginarios, que están en uso en las diferentes provincias de España é islas adyacentes», Boletín de la Real Academia de la Historia, 33, pp. 202-217.

SÁNCHEZ MARTín, F. J. y M. SÁNCHEZ ORENSE (2011): «La metrología en el primer tratado de sastrería español del siglo XVI: cuestiones terminológicas sobre la voz vara», Sintagma, 23, pp. 71-83.

SÁNCHEZ ORENSE, M. (2012): La fortificación y el arte militar en los tratados renacentistas: estudio lexicográfico, Tesis Doctoral inédita, Universidad de Salamanca.

TEN Ros, A. (1989): «El sistema métrico decimal y España», Arbor, 527-528, CXXXIV, pp. $101-121$.

TEN Ros, A. (2000): «Viejos y nuevos sistemas metrológicos», en S. Garma, Exposición Año Internacional de las Matemáticas. Disponible en http://museovirtual.csic.es/ salas/medida/medidas_matematicas [Consulta: 06/11/2011].

TEN Ros, A. (2002): «La metrología castellana en el siglo XVIII», en L. García Ballester, coord., Historia de la Ciencia y de la Técnica en la Corona de Castilla, Valladolid, Junta de Castilla y León, IV, pp. 403-416. 